Giselle Reis Brandão ${ }^{a}$

(iD) https://orcid.org/0000-0002-9932-5758

Maria Elizabeth Antunes Lima ${ }^{\text {b }}$

(D) https://orcid.org/0000-0002-6612-1644

Pontifícia Universidade Católica

de Minas Gerais (PUC-Minas),

Departamento de Psicologia.

Betim, MG, Brasil.

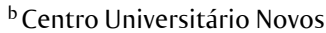

Horizontes. Belo Horizonte, MG ,Brasil.

Contato:

Maria Elizabeth Lima

E-mail

antuneslima15@gmail.com

Os autores declaram que o estudo não foi subvencionado e que não há conflitos de interesses.

Os autores informam que o trabalho não foi apresentado em eventos científicos.

Ensaio baseado em tese de doutorado de Giselle Reis Brandão, intitulada Uma investigação em Clínica da Atividade junto aos cuidadores de pessoas com deficiência mental em uma organização privada em Minas Gerais, defendida em 2012 na Universidade Federal de Minas Gerais (UFMG).

\section{Uma intervenção em Psicopatologia do Trabalho - contribuições da Clínica da Atividade}

\author{
An intervention in Psychopathology of Work - \\ Clinic of Activity contributions
}

\section{Resumo}

O ensaio trata das contribuições da clínica da atividade para a intervenção nos contextos laborais. Partindo da constatação de uma lacuna presente na psicopatologia do trabalho quanto ao desenvolvimento de métodos para reduzir ou prevenir os fatores patogênicos nesses contextos, faz-se um resgate da proposta de intervenção da clínica da atividade. Para ilustrar a importância das bases teórico-metodológicas desenvolvidas nesse campo de estudos, é relatada uma intervenção que visou reduzir os problemas enfrentados por profissionais responsáveis pelo cuidado de pacientes com graves deficiências físicas e mentais. Os resultados revelam alguns desenvolvimentos ocorridos na atividade do cuidador, ampliando seu poder de agir, revitalizando o gênero profissional e minimizando impactos em sua saúde mental, o que sugere um diálogo profícuo entre essas áreas.

Palavras-chave: Psicopatologia do Trabalho; Clínica da Atividade; intervenção; saúde mental.

\begin{abstract}
The essay deals with the contributions of the Clinic of Activity to the intervention in labor contexts. Based on the acknowledgment of a gap in the Psychopathology of Work regarding the development of methods to reduce or prevent pathogenic factors in these contexts, the authors rescue the Clinic of Activity intervention proposal. To illustrate the importance of theoretical-methodological bases developed in this field of study, they reported on an intervention aimed at reducing the problems faced by professionals responsible for the care of patients with severe physical and mental disabilities. The results reveal some developments in the caregiver's activity, extending their power to act, revitalizing the professional genre and minimizing impacts on their mental health, which suggests a fruitful dialogue between these areas.
\end{abstract}

Keywords: Psychopathology of Work; Clinic of Activity; intervention; mental health. 


\section{Introdução}

Desde seu nascimento na França, no período imediatamente posterior ao final da Segunda Guerra Mundial $^{1}$, a psicopatologia do trabalho enfrenta dois problemas principais: o estabelecimento do nexo entre transtornos mentais e trabalho e o desenvolvimento de formas de intervenção que permitam prevenir esses transtornos ou reduzir seus impactos. Embora ambos os problemas sejam cruciais para sua consolidação enquanto disciplina capaz de oferecer respostas efetivas para as questões de saúde nos contextos laborais, o principal foco das pesquisas tem sido a busca de soluções para o primeiro deles, deixando para o segundo plano as ações de intervenção. Mesmo tendo ocorrido uma tentativa de formalizar uma proposta de intervenção, durante os anos 1980, por C. Dejours², esta foi modificada substancialmente pelo próprio autor, quando publicou o Addendum de 1993, propondo a psicodinâmica do trabalho como uma nova disciplina ${ }^{3,4}$. O próprio título do Addendum, "Da psicopatologia à psicodinâmica do trabalho", já anunciava a mudança de perspectiva do seu autor. A partir de uma reflexão em torno do período que se passou entre a primeira e a segunda edição de Travail, usure mentale (publicado no Brasil, em 1987, com o título A loucura do Trabalho - estudo de psicopatologia do trabalho), C. Dejours $^{3}$ admitiu que o ensaio de 1980 tematizava sobre "certas intuições e abria algumas pistas de pesquisa", mas não "constituía um programa científico stricto sensu"3 (p. 203). Assim, qualificou a psicopatologia do trabalho como "demasiadamente estreita para responder às novas questões", dizendo que isso o obrigou "a vislumbrar uma perspectiva mais ampla: a psicodinâmica do trabalho"3 (p. 204). Seu propósito consistia, portanto, em "substituir a psicopatologia do trabalho pela nova denominação análise psicodinâmica das situações de trabalho"3 (p. 204), já que as "críticas cada vez mais abundantes provocadas pela denominação 'psicopatologia do trabalho' como disciplina" geraram a necessidade de reconhecer "o deslocamento qualitativo que foi ganhando corpo após 1980", quando operou uma "passagem da patologia à normalidade" 3 (p. 207). Em suma, ao considerar a psicodinâmica do trabalho como a psicopatologia do trabalho "sob sua nova forma" ${ }^{3}$ (p. 208), o autor se distanciou da nossa perspectiva, que consiste em reafirmar a importância da psicopatologia do trabalho, desde suas origens, além de preservar sua denominação que ainda nos parece adequada.

Cabe ressaltar que a opção pelo nexo causal decorreu da necessidade de se encontrar respostas a duas questões essenciais: é possível atribuir ao trabalho a origem, o desenvolvimento ou o agravamento de certos transtornos mentais? E, caso isso se revele verdadeiro, de que maneira poderia ser demonstrada tal relação? As pesquisas realizadas em torno dessas questões vêm permitindo um avanço considerável da disciplina, tornando-a um legítimo campo de estudos entre os que se dedicam a estudar as relações saúde/trabalho. No entanto, é possível pensar que, ao privilegiar a busca por essas respostas, a psicopatologia do trabalho deixou de avançar no desenvolvimento de métodos favoráveis à promoção da saúde nos contextos laborais ${ }^{5,6}$.

Neste ensaio, pretendemos contribuir para a resposta ao segundo problema, propondo um caminho de intervenção em psicopatologia do trabalho por meio de uma perspectiva inovadora vinda da clínica da atividade (CA).

\section{As bases teórico-metodológicas da psicopatologia do trabalho}

A primeira menção à psicopatologia do trabalho ocorreu em um ensaio publicado por Paul Sivadon, em 1952, no qual o teórico francês, não apenas nomeou a nova disciplina, como trouxe elementos importantes para pensar a respeito das relações entre saúde mental e trabalho. Já naquele momento ele se interrogou sobre a possibilidade de o trabalho provocar distúrbios mentais ou favorecer sua eclosão, argumentando que, embora para alguns esta questão fosse descabida, a distribuição das neuroses na população, em geral, não lhe parecia casual: elas eram mais frequentes no meio urbano do que no rural e mais evidentes no meio industrial do que no artesanal ${ }^{7}$.

Mas, nesses primórdios da disciplina, quem proporcionou os maiores avanços foi Louis Le Guillant, ao trazer contribuições decisivas para as práticas diagnósticas. Seus estudos em torno dos distúrbios que afetavam as telefonistas, os mecanógrafos, os condutores de trem e as empregadas domésticas continuam sendo uma referência para os pesquisadores da área. Além disso, sua abordagem diagnóstica pluridimensional, baseada no tratamento amplo e profundo do fenômeno estudado, considerando-o em todas as dimensões, ainda permanece válida ${ }^{8}$.

No entanto, a despeito dessa importante contribuição para o diagnóstico, Le Guillant não propôs um método de intervenção nos contextos laborais. Embora tenha enfatizado que devemos priorizar o cuidado com o trabalho - transformando-o de modo a adequá-lo às necessidades humanas, ao invés de esperar que as pessoas se ajustem a suas exigências -, ele não desenvolveu uma forma de intervir que permitisse dar um sentido concreto a tal premissa ${ }^{8,9}$. 
Clot $^{9}$ admitiu igualmente uma falha em Le Guillant quando este considerou a atividade de trabalho como um objeto de análise e não um meio de ação, dizendo que a incorporação de tal perspectiva pela psicopatologia do trabalho poderia ter mudado seu rumo, aproximando-a mais do que denominamos, hoje, clínicas do trabalho. Assim, ao concordar com as visões de Tosquelles e Daumézon a respeito da atividade, o autor reconheceu que poderiam "ter conduzido a uma evolução bastante diferente da psicopatologia do trabalho"9 (p. 75), uma vez que a atividade de trabalho era vista por ambos "não só como um objeto de análise, mas como meio de ação" ${ }^{9}$ (p. 75). Para ele, é nesse ponto preciso da atividade de trabalho, "considerada como meio de restauração da saúde, que Le Guillant se afasta mais daquilo que é designado [...] por clínica do trabalho”9 (p. 78).

\section{Uma intervenção em psicopatologia do trabalho - contribuições da clínica da atividade}

Ao fazer essa revisão crítica em torno dos fundamentos da psicopatologia do trabalho, propondo uma nova maneira de intervir nos contextos laborais, a CA se apresenta como um espaço de interlocução para aqueles que tentam desenvolver ações mais eficazes no âmbito da saúde do trabalhador. Ademais, entre as diversas correntes que compõem as clínicas do trabalho, ela representa uma das abordagens mais profícuas, não apenas por sua concepção de atividade, mas também pela compreensão de seu potencial na clínica ${ }^{9,10}$. Constituída a partir do final dos anos 1990, por Yves Clot e sua equipe no Conservatoire National des Arts et Métiers (CNAM), em Paris, a CA se fundamenta em teóricos como L. Vygotski, A. Wisner, L. Le Guillant, I. Oddone, M. Bakhtin, possibilitando um rico diálogo entre eles e suas áreas do conhecimento: psicologia, ergonomia, psicopatologia do trabalho e linguística.

Sua primeira premissa afirma que a análise deve ser feita no "ambiente habitual" dos sujeitos envolvidos, isto é, onde são confrontados com as dificuldades e criam soluções para enfrentá-las. Nesse sentido, seu foco são as "habilidades anônimas, representações do senso comum, análises da razão prática e subjetiva daqueles que trabalham"11 (p. 127). Seu foco consiste, antes de tudo, em transformar as situações de trabalho, sendo os trabalhadores os próprios protagonistas dessa transformação. Eles são retirados da posição de observados e colocados na de observadores e coatores no processo. Ocorre então uma releitura da perspectiva clássica da psicopatologia do trabalho, não apenas pelo foco privilegiado na ação, mas também pela incorporação da emoção e do afeto, que passam a ser concebidos como atividade e, ainda, instrumentos do desenvolvimento dos sujeitos envolvidos.

Mas para ter acesso à dimensão afetiva é preciso alcançar o real da atividade, isto é, deve-se acessar não apenas aquilo que é realizado pelo trabalhador, mas também o que ele é impedido de fazer, aquilo que não realiza. Nesse contexto, portanto, a atividade não se limita mais ao que se faz, mas inclui o que não é feito, o que se gostaria de fazer, o que deveria ser feito, o que poderia ter sido feito, o que precisa ser refeito e mesmo o que se faz sem querer fazer ${ }^{11}$.

Ao tentar buscar meios para acessar as emoções e os afetos presentes na atividade, Clot $^{11}$ compreendeu que o maior risco consiste em tentar lhes atribuir sentido a partir de um olhar externo. Isso o levou a propor quadros de análise que permitissem ao sujeito interpretar a experiência vivida. Assim, apoiando-se na premissa vygotskiana de que "é somente em movimento que um corpo se revela" 12 (p. 64), a CA vem desenvolvendo métodos que fazem parte de um quadro dialógico: autoconfrontações simples e cruzada e instrução ao sósia.

Cada um desses métodos se insere numa perspectiva metodológica mais ampla, que orienta a intervenção e busca construir condições e princípios de funcionamento, de cunho histórico-desenvolvimental, que servirão de base para se estabelecer uma relação com os atores envolvidos: os trabalhadores, a hierarquia, o sindicato ou a associação. Tudo isso compõe um quadro metodológico visando à realização do propósito maior dessa clínica: o desenvolvimento da atividade.

Na origem desse processo está uma problemática apresentada pelos trabalhadores e/ou pela hierarquia, sendo que a maneira como é trabalhada reflete não somente uma lógica voltada para o desenvolvimento, mas coloca, no centro do debate, a atividade profissional. $\mathrm{O}$ tratamento das diversas perspectivas do problema levantado permite construir uma demanda representativa do coletivo de trabalho. Finalmente, por meio de um comitê de decisão, composto por profissionais pertencentes às várias instâncias da organização, procura-se discutir e legitimar as decisões, negociações e ações que decorram do processo da intervenção ${ }^{9}$.

Tenta-se, ainda, criar um quadro que possibilite aos trabalhadores compreenderem que a ação individual se define necessariamente por uma perspectiva coletiva, pois se baseia no compartilhamento de elementos comuns (regras, resultados, interpretações coletivas). Nesse sentido, torna-se fundamental o diálogo entre eles, de maneira a contemplar a variabilidade da atividade e seus 
conflitos. Assim, poderão identificar seus recursos de ação e construir outros, incrementando seu poder de agir, sendo que esse trabalho coletivo de análise da atividade é também conhecido como metodologia de coanálise ${ }^{13}$.

Outro construto teórico fundamental consiste no conceito de ofício, composto pelas regras formais (impessoal), as trocas entre os profissionais (interpessoal), os modos singulares de se apropriar da atividade (pessoal) e a história comum do coletivo (transpessoal) ${ }^{9}$. Conhecidos como instâncias do ofício, esses componentes atuam referenciando o trabalhador (individual e coletivamente) em maneiras de fazer e de ser naquele meio profissional, unindo o passado e o presente. Ademais, oferecem direção e amparo frente aos conflitos e riscos da atividade ${ }^{9}$.

A instância transpessoal, também conhecida como gênero profissional ${ }^{11}$, torna-se referência nesse construto, pois ela representa o patrimônio social da atividade, perpassado pelas demais instâncias e corporificado pelas histórias diversas que o compõem: histórias locais e da categoria, regras comuns, negociações, enfim, tudo o que define aquele meio profissional. Essa memória genérica possibilita ao indivíduo antecipar os efeitos da ação, apoiando-se nela para tomar decisões, além de se tornar um sistema de apoio à atividade, tanto do ponto de vista técnico quanto psicológico, sendo por isso mesmo, favorável à saúde.

Em suma, no âmbito da CA, a intervenção é concebida como "um desenvolvimento transpessoal da função do coletivo", contendo "três grandes fases metodológicas"14 (p. 73). Na primeira, a partir de uma comanda, "se organiza a instância dialógica, em resposta ao conflito de critérios sobre a qualidade do trabalho"14 (p. 72), envolvendo representantes do pessoal, direções operacionais e aqueles que atuam na área da saúde. Nessa fase, são analisadas situações ordinárias por coletivos de profissionais da base da hierarquia, isto é, aqueles que conhecem o ofício. A segunda fase "engaja profissionais voluntários na análise de atividades ordinárias contrariadas". Trata-se do conflito em torno do "trabalho bem feito, do prazer e dos desprazeres da controvérsia, sem participação da hierarquia”. Os métodos adotados pretendem desenvolver "a função psicológica do coletivo para imaginar novas possibilidades de agir"14 (p. 72). Finalmente, em um terceiro momento, "os resultados produzidos pelos profissionais sobre suas controvérsias se tornam objetos de outro diálogo instituído no seio da instância inicial. O coletivo muda, então, de lugar na intervenção, tornando-se recurso para modificar a organização do trabalho". Neste momento, a controvérsia profissional se amplia, alcançando outros objetos e destinatários. Ou seja, enquanto, na segunda fase, ela tinha por objetivo "o desenvolvimento transpessoal do ofício", ao se encontrar com "os sindicatos e a direção, os resultados potenciais deste primeiro desenvolvimento, adquirem um estatuto de meio para outro fim: o desenvolvimento impessoal do ofício na organização"14(p. 72).

Portanto, a metodologia em CA prevê o desenvolvimento da atividade em distintos âmbitos de análise: entre os trabalhadores, destes com a hierarquia e nas instâncias de saúde e representativas, além, é claro, do âmbito individual.

\section{A instrução ao sósia: meio para provocar o desen- volvimento da atividade}

Entre os métodos adotados no âmbito da CA, a instrução ao sósia foi escolhida para ser abordada neste ensaio, ilustrando seu uso no contexto de uma intervenção, junto a um grupo de cuidadores de pessoas adultas com deficiências e transtornos diversos.

A prática da instrução ao sósia (IS) remete aos trabalhos de Ivar Oddone, realizados na década de 1960, junto aos operários da Fiat Mirafiori, em Turim, Itália. Esse método indireto foi utilizado com grupos homogêneos de trabalhadores, com o propósito de resgatar sua experiência, produzindo um novo conhecimento sobre o próprio trabalho ${ }^{15}$.

Inspirando-se nessa experiência, a CA desenvolveu o método da IS, que se inicia pela seguinte consigna: "suponha que eu seja o seu sósia e que amanhã eu me encontre em situação de dever substituí-lo em seu trabalho. Quais instruções você deveria me transmitir de modo que ninguém perceba a substituição?"11 (p. 144). Os grupos são compostos por até dez pessoas, e todas as sessões gravadas, seguindo etapas de evolução do acesso à experiência. A cada encontro, um profissional instrui o sósia (o clínico responsável pela intervenção), sendo acompanhado pelos colegas, os quais poderão, posteriormente, atuar também como sósias. Após a instrução, cada profissional recebe sua gravação, devendo escutá-la e registrar, por escrito, aspectos que queira levar para o debate com os colegas, visando uma coanálise.

A IS possibilita que os membros do grupo, individual e coletivamente, organizem, formalizem, validem e transmitam sua experiência. A necessidade de expor o mais detalhadamente possível sua atividade ao sósia abre perspectivas sobre seu fazer, a maioria delas alternativas impensadas ou abandonadas, buscadas, mas não encontradas. O profissional pode se deslocar na sua maneira de ver e de realizar a 
atividade, ocorrendo certo estranhamento em relação àquilo que lhe era habitual. Espera-se, assim, que ocorra uma mudança no estatuto da experiência que, de objeto de análise, se torna um meio para viverem outras experiências ${ }^{9}$.

A clínica da atividade como recurso para a psicopatologia do trabalho - breve relato de uma intervenção ${ }^{c}$

A intervenção ocorreu em uma organização privada, cujo propósito é oferecer cuidado a pessoas com deficiências graves (cognitivas, neurológicas, físicas, psicopatológicas), por meio de atendimentos clínicos diversos, cuidados básicos e orientação educacional especial.

O trabalho é organizado em grupos de convivência de internos $^{\mathrm{d}}$, variando entre seis e 12 indivíduos, organizados conforme suas necessidades, sendo acompanhados por cuidadores fixos em cada grupo. A rotina de trabalho é muito intensa, física e psicologicamente, requerendo cooperação entre os cuidadores, atenção direta e flutuante durante todo o tempo, extensiva a todos os internos que estejam no mesmo ambiente. Exige também disciplina quanto aos horários dos cuidados básicos, como atividades de alimentação, banho de sol, higiene, socialização. Esse dinamismo também se deve às necessidades criadas pela própria equipe, decorrentes de ausências, atrasos, férias, saídas para acompanhar os internos. Tais variações ocorrem cotidianamente e impactam, de forma significativa, a atividade dos cuidadores.

A intervenção ocorreu no período de março de 2010 a agosto de 2011, envolvendo seis profissionais (três de cada plantão), que cuidavam do Grupo Especial Masculino (GEM), composto por seis internos cadeirantes com problemas de ordem cognitiva, motora e neurológica. Todos os cuidadores possuíam ensino médio completo, sendo dois técnicos em enfermagem. Havia cinco mulheres e um homem: dois com quatro meses de trabalho na organização e os outros com cinco, oito, 12 e 23 anos.

As instruções ao sósia foram realizadas alternadamente, com dois grupos de cuidadores, dentro dos princípios metodológicos propostos pela CA e descritos acima. O processo envolveu três etapas: uma preliminar, orientada para observações sistemáticas junto ao GEM e sua dinâmica; outra realizada junto ao grupo I de cuidadores, tendo ocorrido nove encontros, informais e formais, destinados a negociações diversas, à escuta dos membros, à apresentação da proposta, ao nivelamento da demanda já construída e à realização das instruções ao sósia; a terceira consistiu em repetir, por meio de sete encontros, com o grupo II de cuidadores, o mesmo formato da etapa anterior.

Embora as fases das instruções ao sósia tenham sido totalmente cumpridas, não foi possível realizar todas as etapas da intervenção proposta pela CA e descritas anteriormente ${ }^{14}$, faltando, sobretudo, uma maior conexão com as instâncias hierárquicas e decisórias. Contudo, isso não impediu que a experiência resultasse em alguns desenvolvimentos por parte dos cuidadores na sua relação com a atividade.

\section{A demanda dos cuidadores: um debate sobre os con- flitos no interior da atividade}

A demanda não se originou da organização, mas da proposta de uma das autoras, a qual identificou alguns aspectos problemáticos nas atividades ali desenvolvidas, por meio de contatos profissionais anteriores: dúvidas quanto aos limites na expressão do afeto em uma relação de cuidado, disputas internas entre os cuidadores e dificuldades em estabelecer os critérios de qualidade no serviço prestado. Tudo isso parecia ter impactos negativos na saúde dos cuidadores.

Uma vez proposta a intervenção, houve grande envolvimento dos profissionais, que elaboraram uma demanda comum em torno de um problema real, endereçada para aquele espaço de discussão. Logo de início, portanto, construíram coletivamente a problemática a ser trabalhada: "O que priorizar? O critério pessoal sobre o que é melhor para o interno ou a preservação de um bom relacionamento com o colega cuidador?” Tal problemática evoluiu para: "Como lidar com as diferentes maneiras de agir dos colegas junto aos internos?" Esta questão refletia uma vivência comum e nociva para as relações profissionais, tornando-se um problema de consciência, já que implicava um conflito de critérios em torno da qualidade do cuidado prestado ao paciente.

Tal questão revelou-se uma ameaça à saúde mental, uma vez que os cuidadores admitiram a grande dificuldade que enfrentavam diante de algumas atitudes dos colegas. Eles se referiam aos excessos alimentares ou outras formas de "negligência" com o interno (por exemplo, deixá-lo solto no pátio). A questão central consistia em como lidar com as situações que revelavam a variabilidade nas formas de apropriação da atividade pelos pares, sendo que algumas delas eram

c A pesquisa foi submetida ao Comitê de Ética em Pesquisa da UFMG - COEP, sob o Registro CAAE - 0562.0.203.000-11 e aprovado no dia 8 de fevereiro de 2012.

d O termo "interno" foi escolhido porque a maioria dos pacientes pertence à modalidade de "atendimento permanente", embora existam outras modalidades. 
percebidas como descuido em relação ao interno. Portanto, a demanda dos cuidadores possuía um sentido clínico, porque se endereçava a um fazer de qualidade, reconhecendo os dilemas presentes nesse fazer. Ela sinalizou, desde o início, a importância de se cuidar do ofício para melhor exercer o ofício de cuidado.

\section{$O$ ofício em cena: a degenerescência do gênero pro- fissional e alguns desenvolvimentos da atividade}

No decorrer do processo, ficou evidente que o gênero profissional não se apresentava naquele contexto como um recurso para a atividade. É sabido que a degenerescência do gênero deixa a atividade privada de recursos (técnicos e psicológicos), limitada a arranjos e meios individuais que possibilitam, em cada situação, um poder de agir ilusório, precário e pontual, não sendo amparado nem alimentado pelas regras formais ou por aquelas oriundas das trocas coletivas.

Várias situações dialógicas revelaram que os cuidadores interpretavam as situações conflitivas, inerentes à atividade, como sendo um problema pessoal, sem vislumbrarem qualquer possibilidade de se pensar a atividade de forma coletiva. Consequentemente incorriam em transgressões arriscadas e, com frequência, recorriam à hierarquia ou faziam chegar até ela informações e queixas que poderiam ser tratadas internamente por eles.

Uma regra organizacional, que expressava os destinos das ações, ilustra bem a questão: "aqui todos cuidam de todos". Isso significava que cada cuidador era responsável por todos os internos que estivessem no mesmo ambiente, ainda que estes pertencessem a outro grupo. Na prática, cumprir tal regra implicava, muitas vezes, negligenciar outra, a do zelo pelo interno sob sua responsabilidade, expondo-o ao risco. No amplo leque de respostas possíveis, destacaram-se situações em que a transgressão se tornava inevitável e ocorria a intensificação do conflito direto com o colega ou com o interno, resultando em altos custos psicológicos para o profissional. Esse desvio transgressivo do regulamento conduzia a riscos consideráveis, levando cada um "a errar sozinho diante da extensão das besteiras possíveis”, de acordo com Darré, citado por Caroly e $\operatorname{Clot}^{16}$ (p. 22).

$\mathrm{O}$ apelo à hierarquia ocorria quando o profissional se via desprovido de referências para agir e prestes a realizar uma ação desregrada ou uma transgressão, revelando seus limites. A hierarquia, por sua vez, sem possuir recursos para resolver tais situações, reforçava o vazio de uma referência coletiva, aderindo frequentemente ao protecionismo.

Um exemplo ilustra tal questão. Joana ${ }^{\mathrm{e}}$ cuidava de Cláudio, mas com frequência se via na obrigação de cuidar de outro interno, oriundo de outro grupo, quando este se deslocava para outras áreas. Neste embate para atender a duas regras sem perder a qualidade do atendimento, a saída que encontrava era deixar Cláudio e procurar o outro interno. Na volta, passava pelo posto de enfermagem, onde ficava a supervisora e, por meio dessa estratégia, se resguardava de possíveis repreensões por ter deixado seu paciente. Ou seja, ela se mostrava atenta à regra e, ao mesmo tempo, denunciava a distração do colega, obtendo o apoio da hierarquia. Esse e outros exemplos revelaram como cada um agia de forma isolada e com recursos precários (do ponto de vista técnico e psicológico), aumentando os riscos da atividade e reduzindo a eficiência ${ }^{9}$, além de afetar as relações entre os pares.

A IS foi efetiva ao trazer à tona questões próprias das dimensões do ofício, possibilitando o debate entre os cuidadores em torno dos modos de cuidar e de como se impor frente aos colegas experientes. Além disso, permitiu que discutissem sobre o cumprimento das regras, o motivo pelo qual alguns podiam descumpri-las sem sofrer punições, e sobre a definição de cuidado.

O ofício era o objeto e um instrumento técnico e/ou psicológico desse debate, possibilitando-lhes recriar seu fazer individual e coletivo, integrando passado, presente e futuro. Por meio da intervenção ocorreram alguns desenvolvimentos psicológicos e, por terem sido compartilhados através do método, deixaram de se restringir ao portador, tornando-se passível de alimentar e a dinamizar outros movimentos possíveis nas várias vidas do ofício.

Isso ocorreu com Moisés, um profissional com oito anos de casa que estava como cuidador parti$\operatorname{cular}^{f}$ de um interno, mas que se integrava ao GEM, ajudando os colegas com sua força física e experiência, já que se tratava do grupo de internos com maior dependência física e cognitiva. Na fase final das instruções do seu grupo, quando cada cuidador se expressava a respeito da escuta de sua IS e sobre sua vivência da intervenção, ele apresentou um texto escrito, transcrito a seguir, acompanhado de parte do diálogo ocorrido naquele momento:

e Todos os nomes adotados neste trabalho são fictícios.

f Em relação à distribuição dos cuidadores nos grupos, a organização oferece modalidades distintas: cuidador particular; cuidador alocado no grupo de internos (maioria); e cuidador de referência. 
$82^{g}$ Moisés: Na minha fala lá dentro da gravação, eu percebi uma coisa que eu já sabia. Eu trabalhava esse tempo todo que eu trabalho aqui, as minhas atitudes, os meus atos. Eu faço e reflito. E fico pensando o porquê que as pessoas não pensaram igual a mim, tá? Eu penso assim: "puxa, mas hoje eu trabalhei, eu consegui vencer aquele menino que estava agitado"; "eu fiz isso, eu fiz aquilo, será que ninguém reconheceu?" "Será que ninguém viu?" Então, diante disso aí, eu fui e escrevi todas essas coisas aqui que eu vou ler direto e depois a gente discute elas. [Moisés lê pausadamente o que escreveu]

"Meu trabalho é continuação do trabalho do outro. As diferenças e divergências de cada cuidador é que fazem a missão fluir, pois eu vejo com uma dimensão e o outro colega vê com outra. Isso faz que várias cabeças pensam mais, chegando a uma só conclusão, para atender ao outro com mais precisão possível. Eu sempre desempenhei o meu papel pensando na pele do outro; minhas decisões são tomadas depois de experimentadas em mim, mentalmente. Sei que meu trabalho é cansativo, perigoso, emocionante. Mas alguém tinha que fazê-lo, então, estou aqui. Muito feliz por ser uma profissão que nos dias de hoje está no auge e isso me envaidece, me traz fama, além do dinheiro. Saber que sou útil nessa função me traz imensa alegria. Meu emprego, projeto da minha vida. Aí, eu repito aqui: a instrução ao sósia me fez pensar mais ainda sobre o meu papel, me fez ser mais prudente, mais cauteloso. Sei que, nessa profissão, tem que ser de tudo um pouco, tem que... eu tenho que ser mãe, eu tenho que ser pai eu tenho que ser mulher. Tenho que ser mãe, pai, menino, menina; eu tenho que ser moço, eu tenho que ser rapaz, eu tenho que ser avô, eu tenho que ser avó, eu tenho que ser irmão, padrinho, amigo, colega, cunhada, sogro, sogra, eu tenho que ser crente, eu tenho que ser católico. Às vezes, eu tenho que ser surdo, às vezes, eu tenho que ser mudo, só não sou Deus porque o próprio Deus mora dentro de mim".

83 Moisés: E, quando eu falo que eu tenho que ser moça, eu tenho que ser mulher, rapaz, porque cada menino tem uma diferença, né, Ana?

84 Ana: Cada menino...
85 Moisés: Às vezes, é a minha posição de homem ali, naquela hora, ele não vai obedecer; ele vai obedecer, igual a Rose (interna) te obedeceu. Você fez um papel, nem de mãe, foi um papel de avó, então, na hora ela estava precisando de ouvir era aquilo e aquilo era o que convenceu ela.

86 Ana: Eu falei para ela que subisse, que eu ia contar historinha para ela, né? Então, como se diz, com muito custo, ela subiu. Eu cheguei no quarto, deitei ela, assentei na cama dela, contei algumas historinhas

87 Moisés: Aí, se isso não valesse, você ia ter que chamar uma pessoa, com outra personalidade. Vou chamar uma pessoa enérgica aqui, com papel de cunhado chato: "Menina! sobe agora e chega de bobeira!"

88 Ana: Às vezes, nem ele resolveria.

89 Moisés: Nem ele resolveria. Aí, vai ter que ser aqui um papel de... vamos ver de quem?

90 Carla: De elogiar. Ela gosta muito disso!

91 Moisés: "Oh, meu amorzinho, vamos brincar de bonequinha?". Aí, você ia ter que entrar no mundo dela e ficar...

92 Ana: Mas é isso o que a gente faz: entra no mundo deles. É igual ao papel de antigamente, que eu falei: eu assentava com o Ivo (interno) e conversava com ele, até que ele resolvesse levantar e ir.

93 Moisés: É igual assim, quando eu comecei a trabalhar aqui e o CDzinho [referindo-se à gravação da sua IS] fez eu entender isso, porque eu não conseguia entender as diferenças dos colegas. Eu achava que todo mundo tinha que agir com emoção, que todo mundo tinha que ser mágico, não sei o quê, né? Mas, aí, eu vi que cada pessoa tem uma personalidade e que aqui na escola precisa exatamente disso, de todas essas pessoas. Precisa de uma pessoa lerdinha para domar aquele menino; precisa de uma valentona para carregar aquele; precisa de um bom de lábia para levar aquela outra.

g Nesta abordagem, as falas que compõem os diálogos estabelecidos entre os trabalhadores são enumeradas, para evidenciar a sequência dos desenvolvimentos desta atividade dialógica, facilitando sua identificação e a evolução do possível desenvolvimento da atividade. 
94 Intervenant $^{\text {h }}$ : E o quê, exatamente, no CD, te fez ver isso?

95 Moisés: Pois é, a escuta me fez ver por que quando a Ana fala que ela gosta mais de agir com os meninos mais molinhos [dependentes]. Então, ela tem lábia, ela tem domínio de mãe, de avó, ela é meiga, carinhosa para lidar com esses meninos. E eu já não tenho essa lábia [...].

Ao longo do processo, Moisés desvelou progressivamente seus debates interiores sobre a atividade, interrogando as diferenças nas formas de cuidar, o seu próprio estilo de cuidado e o reconhecimento de seu trabalho. No extrato 82, ele propôs um novo caminho, posicionando-se afirmativamente frente ao seu fazer, entendido como continuidade do trabalho alheio, incluindo as diferenças, transformadas agora em recursos para sua própria ação. No processo dialógico, ficou evidente que Moisés não se incomodava mais com as diferenças no agir dos colegas, entendendo que "elas fazem a missão fluir, fazendo com que várias cabeças pensem mais, chegando a uma só conclusão”.

Lembramos que essas diferenças nas formas de cuidar eram o cerne da demanda posta pelos cuidadores no início da intervenção. Seu texto revelou um deslocamento no seu pensamento, envolvendo diferentes instâncias do ofício e permitindo-lhe chegar a uma resposta acerca da sua concepção sobre o cuidado: ele partiu do pessoal, introduziu o nível interpessoal e aproximou-se do transpessoal. Passou a entender sua própria ação como necessariamente articulada à do colega, mas ultrapassando-a, reconhecendo-se como parte de algo maior.

Ao perceber a atividade como singular e a importância disso para o trabalho fluir no âmbito coletivo, compreendeu que ela não está sempre guiada pela emoção ou mesmo pela feminilidade ou maternidade. Tal questão estava presente no seu debate com Ana, a quem se opunha e criticava, no início da intervenção por apresentar um estilo de cuidar marcado pelas ideias de amor maternal ("ela é mãezona”), feminino (“é preciso ser mulher e mãe, para cuidar?”), permissivo e, segundo ele, que infantilizava os internos.

Vale acrescentar que o estilo adotado por Ana foi objeto de debate entre os cuidadores, desde o momento de construção da demanda. Assim, no extrato 95, ele situou o seu fazer a partir do fazer de Ana, deslocando seu pensamento da instância interpessoal - "ela tem lábia, tem domínio de mãe, de avó, ela é meiga, carinhosa para lidar com esses meninos" - para a pessoal "E eu já não tenho essa lábia” - e interrogando seu estilo profissional. Ele atualizou sua experiência em relação à colega, antes criticada, compreendendo melhor seu fazer, tomando por base seu ponto de vista, situando a maternidade no seu estilo profissional e passando a vê-lo como favorável para "lidar com esses meninos".

Tudo isso produziu efeitos sobre seu próprio fazer e sobre o fazer dos colegas. Afinal, "a atividade psicológica no trabalho é aquilo que se faz no universo dos outros para dele participar ou se separar. É o trabalho assumido pelo sujeito no âmbito do trabalho dos outros”, como lembra $\operatorname{Clot}^{11}$ (p. 65). O método da instrução ao sósia permitiu tal elaboração, evidenciando a presença e as conexões possíveis das dimensões do ofício e alguns desenvolvimentos da atividade psicológica desse profissional, cujos recursos de ação foram ampliados, tanto no âmbito da relação com a colega, quanto na relação com seu próprio estilo. Vale acrescentar que esse movimento se deu junto a um coletivo, cujos sentidos podem ultrapassar aqueles explicitados por Moisés.

Construindo uma perspectiva mais realista para a atividade do cuidador, Moisés rompeu com a perspectiva moral que associa o cuidado apenas com a condição de “puro amor”, de ser mulher, mãe, encontrando caminhos de ação frente às divergências com os internos, os colegas e a organização do trabalho. A IS deu-lhe a possibilidade de elaborar e refletir sobre seu estilo profissional, compartilhá-lo com colegas, amadurecê-lo na materialidade de cada situação, arejando e alimentando suas perspectivas de ação e a dos outros. Para esse cuidador, mas também para seus pares, o ofício funciona, por vezes, como um operador da saúde: eles reviveram suas experiências, no aspecto pessoal (estilo profissional), interpessoal (compreendendo e dialogando sobre a diferença no agir da colega), impessoal (debatendo uma regra institucional e as maneiras de agir a partir daí) e transpessoal (identificando a precariedade dessa instância coletiva e reconhecendo-se em ações individualizadas, embora cientes de que a atividade só se faz no campo da atividade do outro).

Acreditamos que essa experiência favoreceu a saúde desses trabalhadores, não apenas por ter permitido que descrevessem e compartilhassem suas mazelas e riscos, mas sobretudo por terem construído novos caminhos de ação e novos contextos para viverem ${ }^{17}$.

\section{Considerações finais}

Ao colocar a psicopatologia do trabalho como uma das fontes de inspiração para a CA, Clot $^{9}$ admitiu a possibilidade e a necessidade de se estabelecer

h Optou-se por este termo, em francês, julgando-o mais apropriado para nomear o clínico do que a palavra, em português, interventor. 
um diálogo entre esses dois campos do conhecimento. Este ensaio tentou contribuir para a continuidade desse diálogo, trazendo alguns elementos que permitem refletir sobre as possibilidades de intervir nos contextos laborais, prevenindo e/ou minimizando os problemas de saúde.

Apesar de ser uma especialidade recente, cujos resultados ainda não estão consolidados, a CA emerge como um rico espaço de interlocução, sobretudo por trazer uma proposta avessa a qualquer forma de dogmatismo, permitindo que seus princípios sejam postos em prática de forma livre e criativa, desde que sejam respeitadas as necessidades impostas pelo campo.
Ademais, o propósito que guia a intervenção em psicopatologia do trabalho não é em nada diferente daquele que o clínico da atividade tenta alcançar por meio de sua prática. $\operatorname{Clot}^{18}$ (p. 105-106) aponta as pesquisas realizadas por Le Guillant como uma de suas principais fontes de inspiração, afirmando que estas representam um reencontro com a clínica. É nesse sentido que define a CA como "uma clínica da saúde", uma vez que se propõe a "restaurar o possível da atividade”. Seu propósito se une ao daqueles que lançaram as bases da psicopatologia do trabalho quando tenta "modificar [...] situações reais de trabalho degradadas" de modo a "desenvolver o poder de agir" dos sujeitos $^{9}$ (p. 227), conciliando eficiência e saúde.

\section{Contribuições de autoria}

Ambas as autoras contribuíram igualmente no levantamento e na interpretação das informações, na elaboração do ensaio e na aprovação da versão final publicada.

\section{Referências}

1. Billiard I. Santé mentale et travail. L’émergence de la psychopathologie du travail. Paris: La Dispute; 2001.

2. Dejours C. A loucura do trabalho: estudo de psicopatologia do trabalho. São Paulo: Oboré; 1987.

3. Dejours C. Travail, usure mentale: nouvelle édition augmentée. Paris: Bayard; 2000.

4. Lancman S, Sznelwar LI, organizadores. Christophe Dejours: da psicopatologia à psicodinâmica do trabalho. Rio de Janeiro: Ed. Fiocruz; 2004.

5. Clot Y. Prefácio à edição brasileira. In: Lima MEA, organizador. Escritos de Louis Le Guillant: da ergoterapia à psicopatologia do trabalho. Teixeira G, tradutor. Petrópolis: Vozes; 2006.

6. Lima MEA. As questões metodológicas em Saúde Mental e Trabalho: avanços, retrocessos e perspectivas. In: Bendassoli PF, Soboll LA, organizadores. Métodos de pesquisa e intervenção em psicologia do trabalho: clínicas do trabalho. São Paulo: Atlas; 2014.

7. Sivadon P. Psychiatrie et socialités. Toulouse: Érès; 1993.

8. Le Guillant L. Escritos de Louis Le Guillant: da ergoterapia à psicopatologia do trabalho. Petrópolis: Vozes; 2006.

9. Clot Y. Trabalho e poder de agir. Belo Horizonte: FabreFactum; 2010.

10. Dujarier M-A, Gaudart C, Gillet A, Lénel P, éditeurs. L'activité en théories: regards croisés sur le travail. Paris: Octarès; 2016.
11. Clot Y. A função psicológica do trabalho. Petrópolis: Vozes; 2006.

12. Vygotski, L. Mind in society: the development of higher psychological processes. Cambridge, MA: Harvard University Press; 1978.

13. Scheller L. Lélaboration de l'expérience du travail: la methode des instructions au sosie dans le cadre d'une formation universitaire. Education Permanente [En ligne]. 2001[cité le 19 Octobre 2017];1(146):161-73. Disponible: http://www. education-permanente.fr/public/articles/articles. php?id_revue $=146$

14. Clot Y. Activité, affect: sources et ressources du rapport social. In : Dujarier M-A, Gaudart C, Gille, A, Lénel P, éditeurs. L’activité en théories: regards croisés sur le travail. Paris: Octarès; 2016.

15. Oddone I, Re A, Briante G. Redécouvrir l'expérience ouvrière: vers une autre psychologie du travail? Paris: Éditions Sociales; 1981.

16. Caroly S, Clot Y. Du travail collectif au collectif de travail: des conditions de développement des stratégies d'expérience. Comparaison de deux bureaux de Poste. Formation et Emploi [En ligne]. 2004 [cité le 19 Octobre 2017];(88): 43-55. Disponible: http://www.persee.fr/doc/ forem_0759-6340_2004_num_88_1_1737

17. Clot Y. O ofício como operador de saúde. Cad Psicol Soc Trab. 2013;16(Spe):1-11.

18. Clot Y. Entrevista Yves Clot. Cad Psicol Soc Trab. 2006;9(2):99-107. 